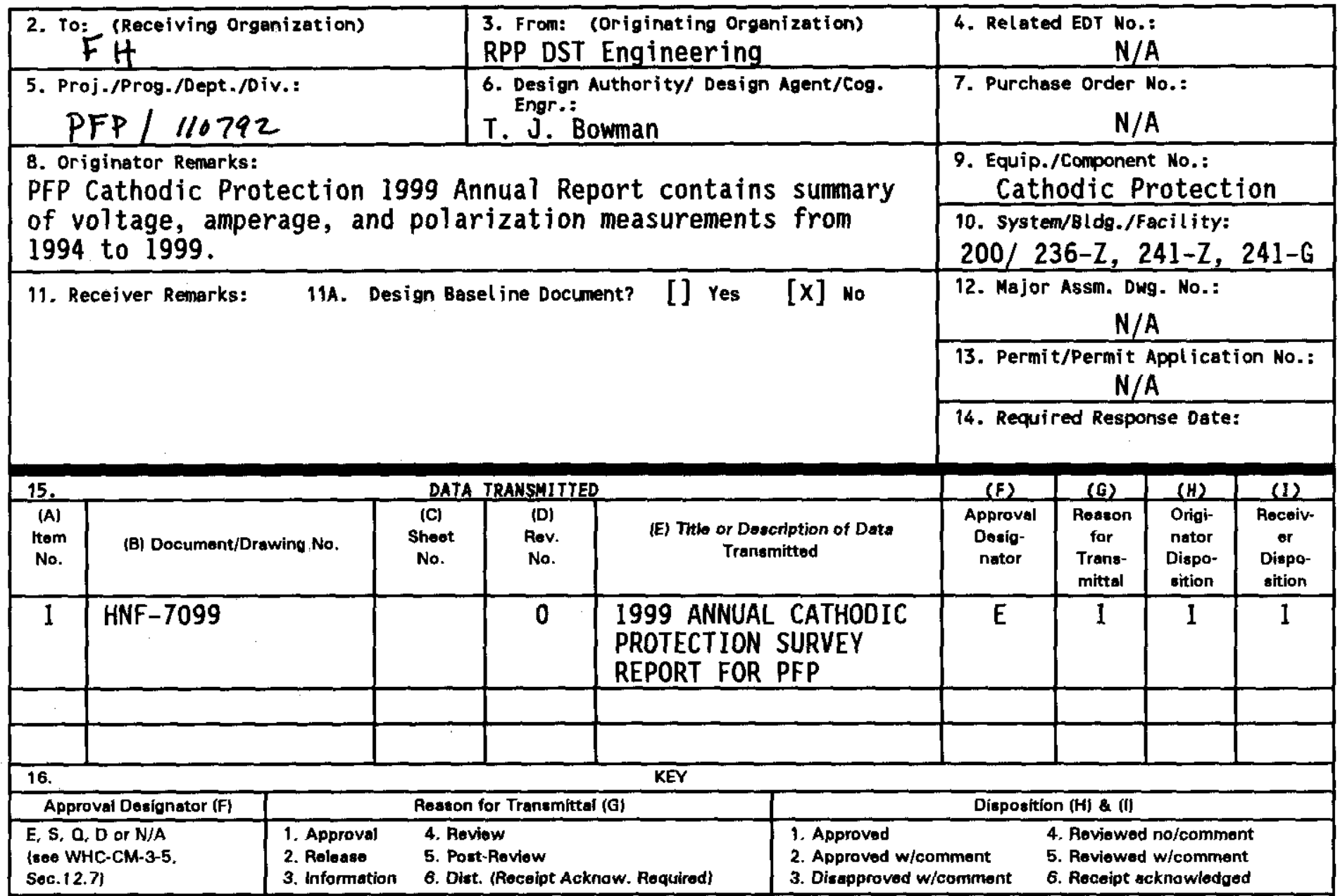

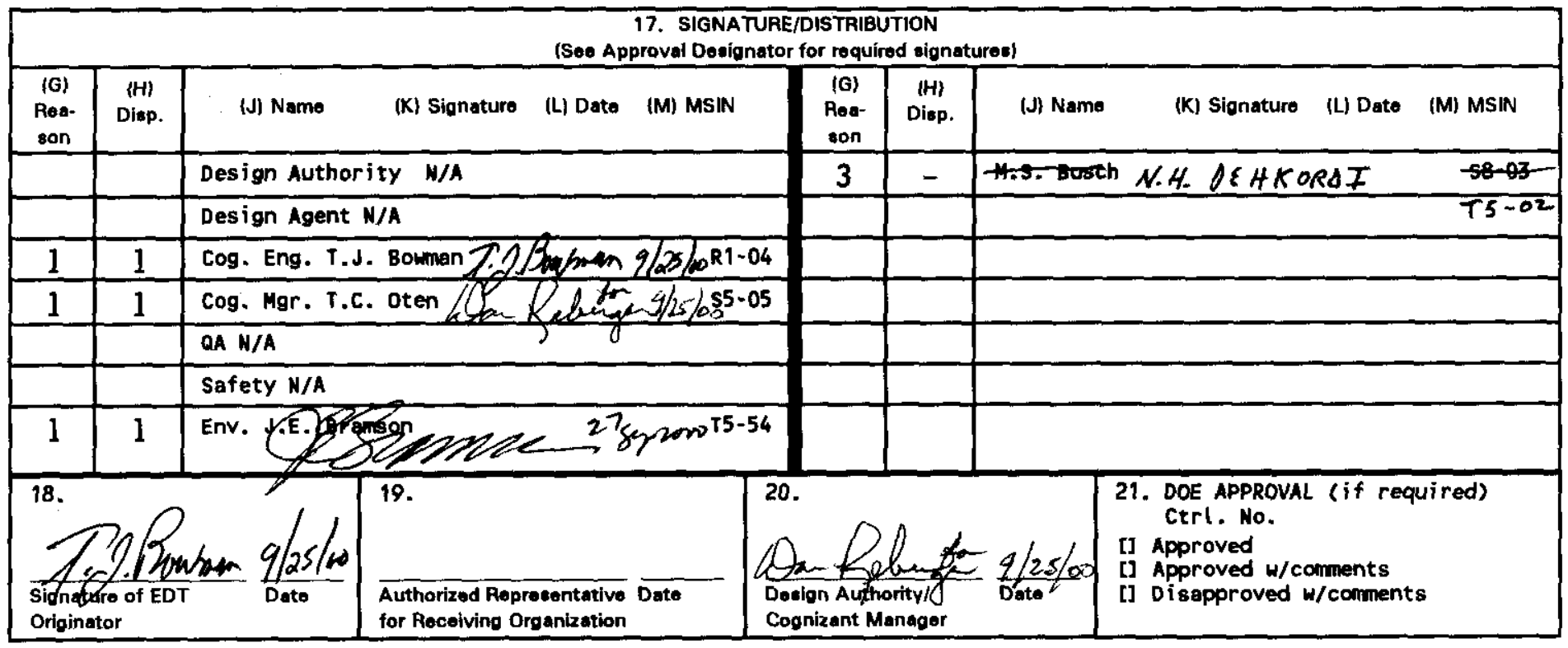

BD-7400-172-2 (05/96) GEF097 
HNF-7099

Revision 0

\section{Annual Cathodic Protection Survey Report for PFP}

Prepared for the U.S. Department of Energy

Assistant Secretary for Environmental Management

Project Hanford Management Contractor for the

U.S. Department of Energy under Contract DE-AC06-96RL13200

Fluor Hanford

P.o. Box 1000

Richland, Washington 


\section{Annual Cathodic Protection Survey Report for PFP}

Document Type: RPT

Division: NMS

T. J. Bowman

CH2MHill

Date Published

September 2000

Prepared for the U.S. Department of Energy

Assistant Secretary for Environmental Management

Project Hanford Management Contractor for the

U.S. Department of Energy under Contract DE-AC06-96RL13200

Fluor Hanford

P.O. Box 1000

Richland, Washington
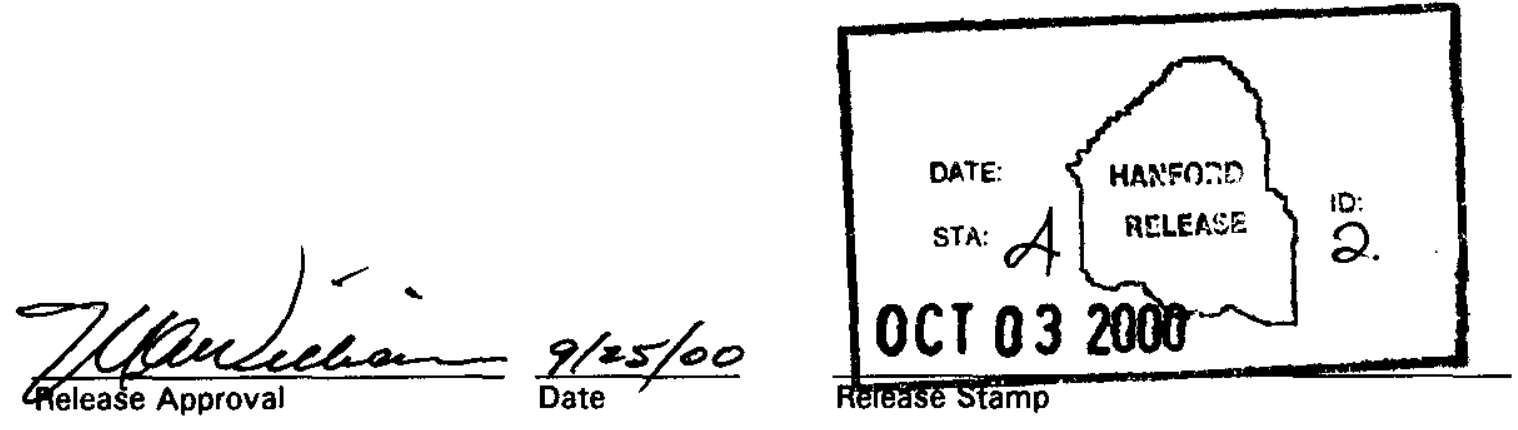
TRADEMARK DISCLAIMER

Reference herein to any specific commercial product, process,

or service by trade name, trademark, manufacturer, or

otherwise, does not necessarlly constitute or imply its

endorsement, recommendation, or favoring by the United

States Government or any agency thereof or its contractors or subcontractors.

This report has been reproduced from the best available copy.

Printed in the United States of Americe

Total Pages: $\quad 28$

HNF- 7099 , sevo 


\section{ANNUAI CATHODIC PROTECTION SURVEY REPORT} FOR PFP

TABLE OF CONTHNTS

TABIE OF CONTHNTS
1.0 INTRODUCTION
2.0 DATA COLLECTION
3.0 1999 POLARIZATION SURVEY RESULTS
4.0 ANALYSIS AND CONCLUSTONS
5.0 RECOMMENDATIONS
6.0 REFERENCES
TABLE 1 Polarization voltages at PFP test stations
TABLE $2 \quad$ Rectifier 45 Efficiency testing
SPREADSHEET 1 ig99 CP Annual survey Data

GRAPHS (Cathodic Voltage Trends and Polarization Voltage Trends from 1994 to 1999)

$\begin{array}{lr}\text { PFP Area - (Rectifier 45) } & 8 \\ \text { Test Station T(R45-1) } & 9 \\ \text { Test Station T(R45-2) } & 10 \\ \text { Test Station T(R45-3) } & 11 \\ \text { Test Station T (R45-6) } & 12 \\ \text { Test Station T(R45-4) } & 13 \\ \text { Test Station T (R45-7) } & 14 \\ \text { Test Station T(R45-8) } & 15 \\ \text { Test Station T (R45-5) } & \end{array}$

PFP Area - TX241-CATH-RECT-102 (Rectifier No. 23)

Test Station $\mathrm{T}(19-1)$

PFP Area - (Rectifier No. 22)

Test Station T(18-11)

Test Station $T(18-9)$

Test station $\mathrm{T}(18-12)$

Test Station $\mathrm{T}(18-4)$

Test Station $\mathrm{T}(18-3)$

Test station $\mathrm{T}(18-2)$

GRAPHS (Rectifier DC Outputs during 1994 to 1999 surveys)

Rectifier 45 volts and amps 
HNF-7099, REV. 0

1999 ANNUAL CATHODIC PROTECTION SURVEY REPORT FOR PFP

\subsection{INTRODUCTION}

This cathodic protection (CP) report documents the results of the 1999 annual $C P$ survey of the underground piping within PFP property. An annual survey of $C P$ systems is required by Washington Administrative Code (WAC).

A spreadsheet to document the 1999 annual survey polarization data is included in this report. Graphs are included to trend the cathodic voltages and the polarization voltages at each test station on PFP property. The trending spans from 1994 to 1999. Graphs are also included to trend voltage and amperage outputs of each rectifier during the annual surveys.

During the annual survey, resistance testing between the underground piping was conducted at each test station. The testing showed that all piping (with test leads into the test stations) was continuous with every pipe represented in the test stations. The resistance data is not documented in this report but can be accessed in work package 2z-99-01003.

During the annual survey, the wiring configurations of anode junction boxes $\mathrm{AJB}(\mathrm{R45-1})$ and $\mathrm{AJB}$ (45-1) were documented. The sketches can be accessed from the JCS work record of work package 2z-99-01003.

Analysis, conclusions, and recommendations of the 1999 annual CP survey results are included in this report.

Not included in this report is the baseline information developed for the 1997 annual report. The 1997 ANNUAI CATHODIC PROTECTION SURVEY REPORT FOR PEP, HNF-3389 Rev, 0, contains the following information:

1. A detailed description of the layout of the CP systems and protected piping systems on the PFP property;

2. Time sequences involved in the collection of annual survey data from 1994 through 1997 ;

3. CP criteria at the Hanford site;

4. River Protection Project (RPP) CP system testing procedure and CP system configurations during annual surveys;

5. 1994 to 1997 CP survey data of voltage and continuity measurements at the test stations on PFP property;

6. Spreadsheets and tables to tabulate the 1994 to 1997 data;

7. Analysis, conclusions, and recommendations of the 1997 annual CP survey results;

8. Tables listing the attributes of the three rectifier systems on PEP property;

9. Table listing the attributes of the PFP area piping;

10. Tables listing continuity measurements during the 1996 and 1997 annual surveys;

11. Table listing supplementary amperage testing during the 1997 annual survey;

12. Table listing the nameplate output data of the three rectifiers associated with PFP property; and

13. Appendix documenting applicable Washington Administrative Code (WAC) requirements and National Association of Corrosion Engineers (NACE) standard recommended practices pertaining to CP criteria of corrosion protection.

\subsection{DATA COLIECTION}

The 1999 annual survey on PFP property was performed per work package 22-99-

$$
-2-
$$


01003. Polarization testing and resistance testing were performed per Tank Farm Maintenance Procedures 3-CATH-357 Cathodic Protection System Testing and 3-CATH-357WT Cathodic Protection System Testing West Tank Farms (WT). The RPP $C P$ cognizant engineer provided the Waveform Analyzer and portable reference electrode and observed the testing.

CP System Configuration During 1999 Annual Survey

Rectifier 45, Rectifier No. 22, and TX241-CATH-RECT-102 (Rectifier No. 23) were equipped with pulse generators during the annual survey. The proper operation of the pulse generators in the DC output circuitry of the rectifier allow the "polarized potential" across the underground piping to be calculated by the Waveform Analyzer.

TX241-CATH-RECT-101 (Rectifier No. 37) was not required to be operational during the survey on the PFP property.

\subsection{POLARIZATION SURVEY RESULTS}

The following table documents the polarization voltages that were calculated by the Waveform Analyzer at the CP test stations during the 10/99 annual PFP area cathodic protection survey. The polarization voltages and the polarization voltage gains are compared against two of the NACE standards implicitly recommended in the WAC. The corrosion rate reduction values in the table are calculated assuming an anodic polarization slope of 0.1 volts per decade of current.

TABLE 1 Polarization Voltages at PFP test station:

\begin{tabular}{|c|c|c|c|c|c|}
\hline 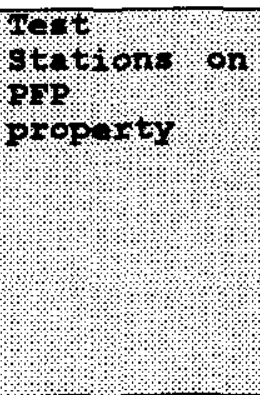 & 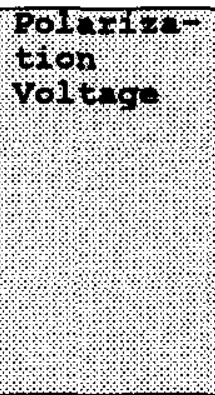 & 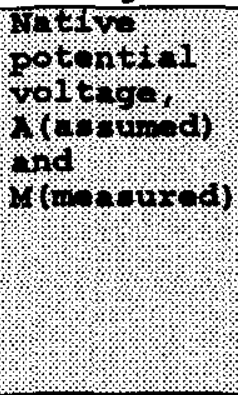 & 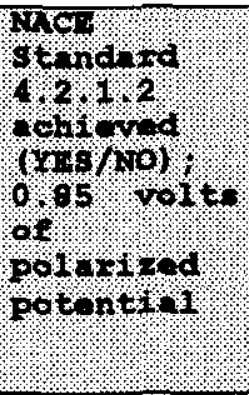 & 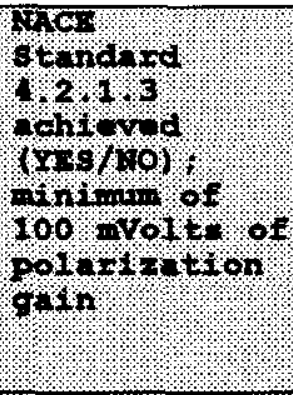 & 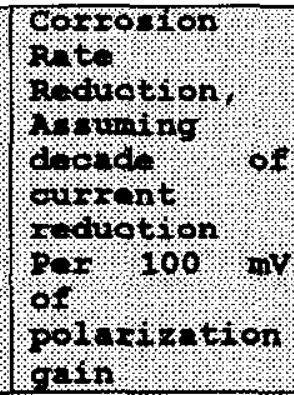 \\
\hline \multicolumn{6}{|c|}{ 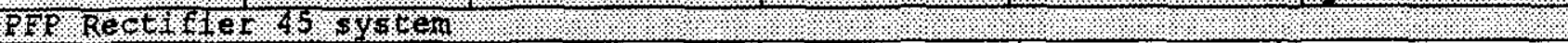 } \\
\hline $4(\mathrm{R} 4 \mathrm{~s}-\%$ & .475 & $.42(\mathrm{M})$ & NO & NO & $\begin{array}{l}55 \mathrm{mV} \text { gain, } \\
3548 \text { rate } \\
\text { reduction }\end{array}$ \\
\hline $1(145-2)$ & .469 & $.42(\mathrm{M})$ & NO & NO & $\begin{array}{l}49 \mathrm{mV} \text { gain, } \\
3098 \text { rate } \\
\text { reduction }\end{array}$ \\
\hline $1(\mathrm{R}+5-3)$ & .744 & $.35(\mathrm{M})$ & NO & YES & $8.7 \mathrm{E} 5 \frac{\mathrm{s}}{8} \mathrm{red}$. \\
\hline $1 \times 1245-4$ & .678 & $.42(\mathrm{~A})$ & NO & YES & $3.8 \mathrm{E} 4 \%$ red. \\
\hline $1(145-5)$ & .801 & $.42 \quad(\mathrm{~A})$ & NO & YES & $6.5 \mathrm{E5} 8 \mathrm{red}$. \\
\hline$+1 \mathrm{k} 45-6$ & .649 & $.42 \quad(\mathrm{~A})$ & NO & YES & $2.0 \mathrm{E} 48 \mathrm{red}$. \\
\hline $1+24-1$ & .758 & $.42 \quad(A)$ & NO & YES & $2.4 \mathrm{E} 58$ red. \\
\hline$(1 \times 45-8)$ & .578 & $.42(\mathrm{~A})$ & NO & YES & 3.8E3\% red. \\
\hline \multicolumn{6}{|c|}{ 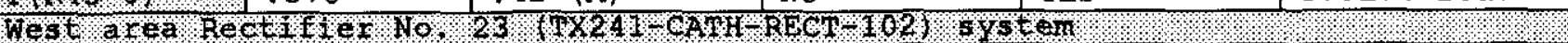 } \\
\hline $119-11$ & .819 & $.42(\mathrm{~A})$ & NO & YES & $9.7 \mathrm{E} 58$ red. \\
\hline \multicolumn{6}{|c|}{ 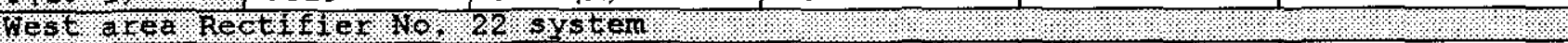 } \\
\hline T18-11 & .91 & $.42(\mathrm{~A})$ & YES & YES & $\begin{array}{l}\text { Insignificant } \\
\text { corrosion }\end{array}$ \\
\hline $188+9$ & .904 & $.42(\mathrm{~A})$ & YES & $\overline{Y E S}$ & $\begin{array}{l}\text { Insignificant } \\
\text { Corrosion }\end{array}$ \\
\hline
\end{tabular}




\begin{tabular}{|c|c|c|c|c|c|}
\hline ABBIS 1 & old a l tate & 3月. YoI & $t=P D P=10 s t$ & $10 \mathrm{~ns}$ & ad) \\
\hline 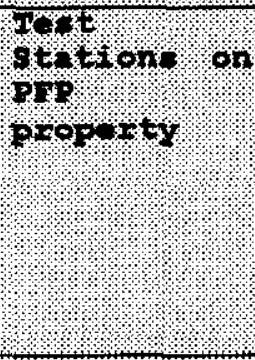 & $160101 \%=1 \%$ & 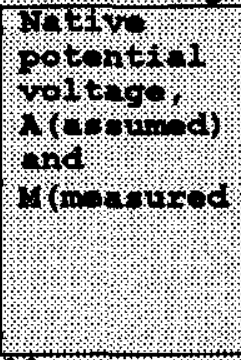 & 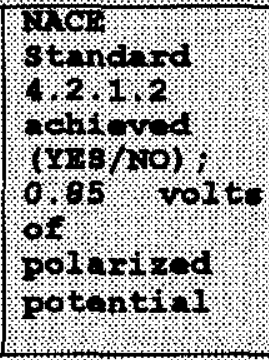 & 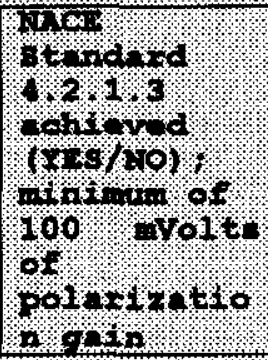 & 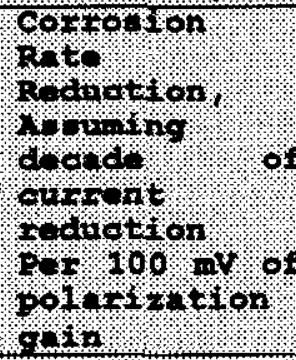 \\
\hline 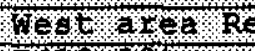 & & 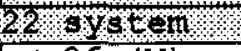 & & & \\
\hline T $(168 \backslash 12)$ & .408 & $<.36(\mathrm{M})$ & N.A. & N.A. & N.A. \\
\hline T/18 & .5 & \begin{tabular}{|l|l}
$.42(\mathrm{~A})$ \\
\end{tabular} & NO & NO & $\begin{array}{l}80 \mathrm{mV} \text { gain, } \\
630 \% \text { rate } \\
\text { reduction }\end{array}$ \\
\hline 1018 & .526 & $.42 \quad(\mathrm{~A})$ & NO & YES & $1.2 \mathrm{E3} 8 \mathrm{red}$ \\
\hline $1718 \div 2$ & .776 & $.42 \quad(\mathrm{~A})$ & NO & YES & $3.6 \mathrm{E5} 8 \mathrm{red}$ \\
\hline
\end{tabular}

See Graphs on pages 8 through 22 of this report to view the cathodic voltage trends and the polarization voltage trends at each test station on the PFP property.

See Graphs on pages 23 through 25 of this report to view the rectifiers DC outputs (voltages and amperages) during the polarization surveys. The graphical trends encompass five years from 1994 through 1999.

\subsection{ANALYSIS AND CONCLUSIONS}

\section{PFP Area - Rectifier 45 syetem performance and output}

Rectifier 45 was running at high efficiency (778) and achieving full-wave rectification during the annual survey. The rectifier was positioned at the D-3 tap settings and outputting $50.1 \mathrm{DC}$ volts/5.01 DC amps to the anode ground bed. The nameplate DC output for Rectifier 45 is 50 volts/12 amps.

None of pipes underneath the eight test stations of the Rectifier 45 system were polarized up to the highest standard, i.e., 0.85 volts.

Pipes underneath six of the test stations gained polarization voltage greater than the recommended minimum, $i$.e., at least 100 millivolts of polarization voltage gain.

The polarization voltages at $T(R 45-1)$ and $T(R 45-2)$ did not meet the recommended minimum, however the piping would realize a reduction in corrosion current by a factor of 3.1 to 3.5 if the piping corrodes at 1 decade of current per 100 millivolts of potential difference.

Polarization voltages at seven of the eight test stations were lower than the voltages measured during the 1997 survey, despite more current being delivered by the rectifier system during the 1999 survey.

The Rectifier 45 is running at its nameplate DC output voltage so no rectifier adjustments should be made to raise the polarization voltages across the piping.

During the 1999 annual survey, Rectifier 45 system resistance was 10 ohms. During the ATP of $8 / 94$, system resistance was 1.55 ohms. The system resistance had increased by a factor of 6.5 in the 5.1 year time span between the ATP and the 1999 annual survey. The trend of system resistance in the last two years indicates a mean value of around 9 ohms. 
HNF-7099, REV. 0

\section{PIP Area - Rectifier No. 22 system performance and output}

Rectifier No. 22 was running at 97.5 DC volts/5.5 DC amps during the 1999 annual survey. The nameplate DC output for Rectifier No. 22 is 120 volts/24 amps .

The piping underneath two of the six test stations of the Rectifier No. 22 system was polarized up to the highest standard, i.e., 0.85 volts. Pipes underneath two other test stations gained polarization voltage up to the recommended minimum, $i . e .$, at least 100 millivolts of polarization voltage gain.

The polarization voltages at $T(18-4)$ did not meet recommended minimum, however the piping would realize a reduction in corrosion current by a factor of 6.3 if the piping corrodes at 1 decade of current per 100 millivolts of potential difference.

Rectifier No. 22 is running at the highest DC output voltage limitation of the test equipment so no adjustments should be made to raise the polarization voltages.

The polarization voltage at $T$ (18-12) is not applicable to NACE standards because the raw water Iine underneath the test station is not designed to be protected.

PEP Area - TX241-CATH-RECT-102 (Rectifier No. 23) syetem performance and output

TX241-CATH-RECT-102 (Rectifier No. 23) was running at 82.5 DC volts/9 DC amps during the annual survey. The nameplate DC output for TX241-CATH-RECT-102 (Rectifier No. 23) is 120 volts/50 amps. With a 100 volt DC limit imposed by the testing equipment, the TX241-CATH-RECT-102 (Rectifier No. 23) system could deliver an additional 17 DC volts to the anode ground bed.

Pipes underneath the one test station on PFP property gained polarization voltage greater than the recommended minimum, i.e., at least 100 millivolts of polarization voltage gain.

\subsection{RECOMMENDATIONS}

Rectifier No. 45 system

1. Continue operating system at existing tap settings; and

2. Apply caution label near Rectifier R45 input circuit breaker, explaining that start-up of rectifier after prolonged shutdown may require temporary tap setting changes due to depolarization of the anode ground bed.

Rectifier No. 22 system

1. Continue operating system at existing tap settings.

TX241-CATH-RECT-102 (Rectifier No. 23) system

1. Continue operating system at existing tap settings.

\subsection{REFERENCES}

HNF-3389, Rev, 0, 1997 Annual Cathodic Protection Survey Report for PFP NACE Standard RP0285-95, Item No. RP02085-95, Standard Recommended Practice, Corrosion Control of Underground Storage Tank Systems by Cathodic Protection WAC 173-303-640 Tank Systems, Washington State Department of Ecology, Dangerous Waste Regulations, Chapter 173-303 WAC, Publication 92-91 H-2-87513 Sh 1 Rev. 1, Elec Cathodic Prot Plan Waste Retention Fac H-2-91019 Sh 5 Rev. 1, Cathodic Protection - Plot Plan Test Stations - Jumpers 
HANF-7099, REV. 0

-Anodes

H-2-91018 Sh 5 Rev. 2, Cathodic Protection - Plot Plan Test Stations - Jumpers -Anodes

TABLE 2

Rectifier 45 Efficiency testing

\begin{tabular}{|l|l|l|l|l|l|l|}
\hline Date & AC Volts & AC Amps & DC Volts & DC Amps & $\begin{array}{l}\text { DC } \\
\text { frequency, } \\
\text { Hz }\end{array}$ & $\begin{array}{l}\text { Output } \\
\text { (assume } \\
\text { pf=.99) }\end{array}$ \\
\hline $11 / 97$ & 116.4 & 1.5 & 29.6 & 3.3 & & 578 \\
\hline $2 / 98$ & 113.9 & 2.04 & 34.9 & 4.75 & & 728 \\
\hline $10 / 99$ & 117.0 & 2.8 & 50.1 & 5.01 & 120 & 778 \\
\hline
\end{tabular}




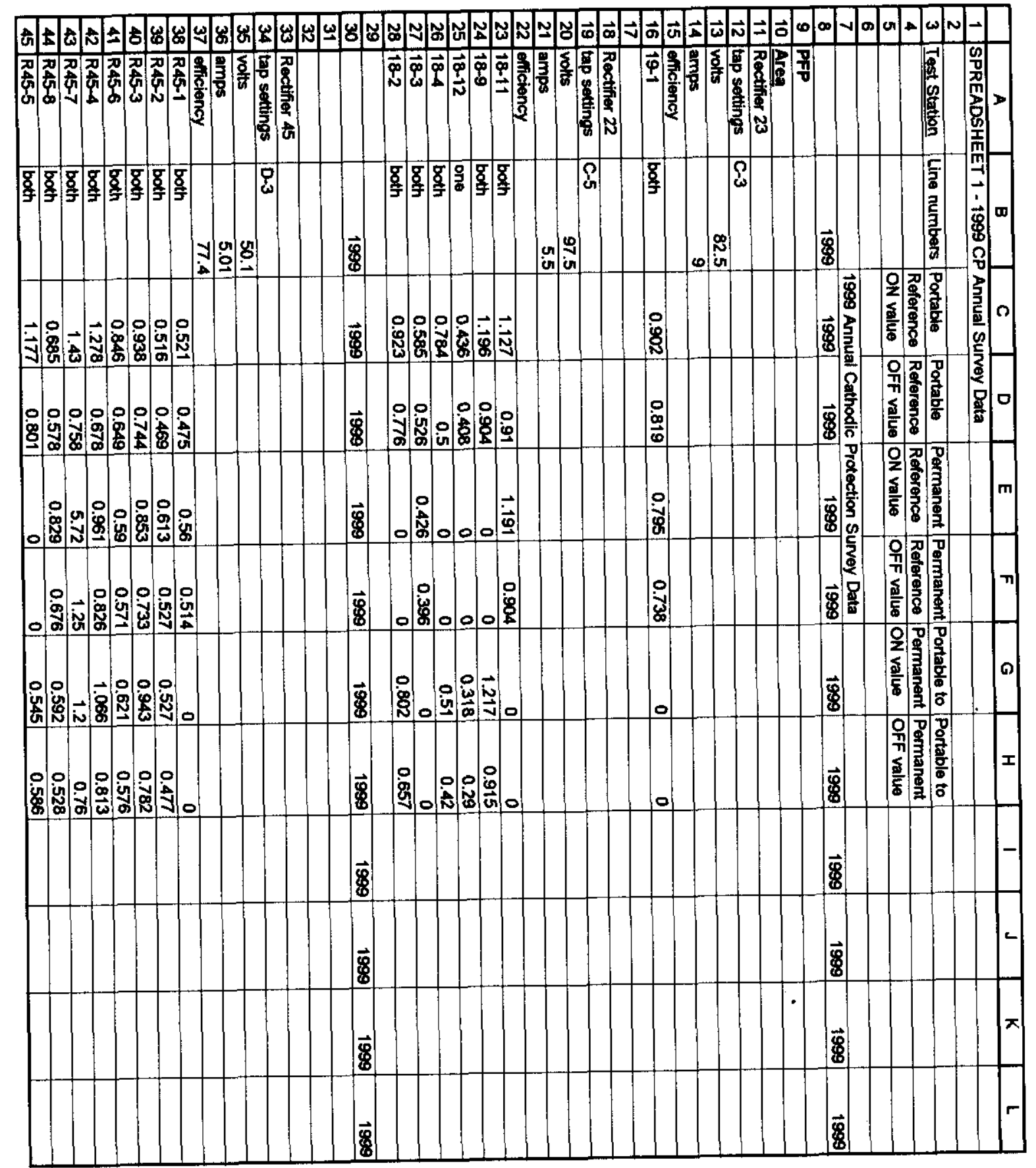




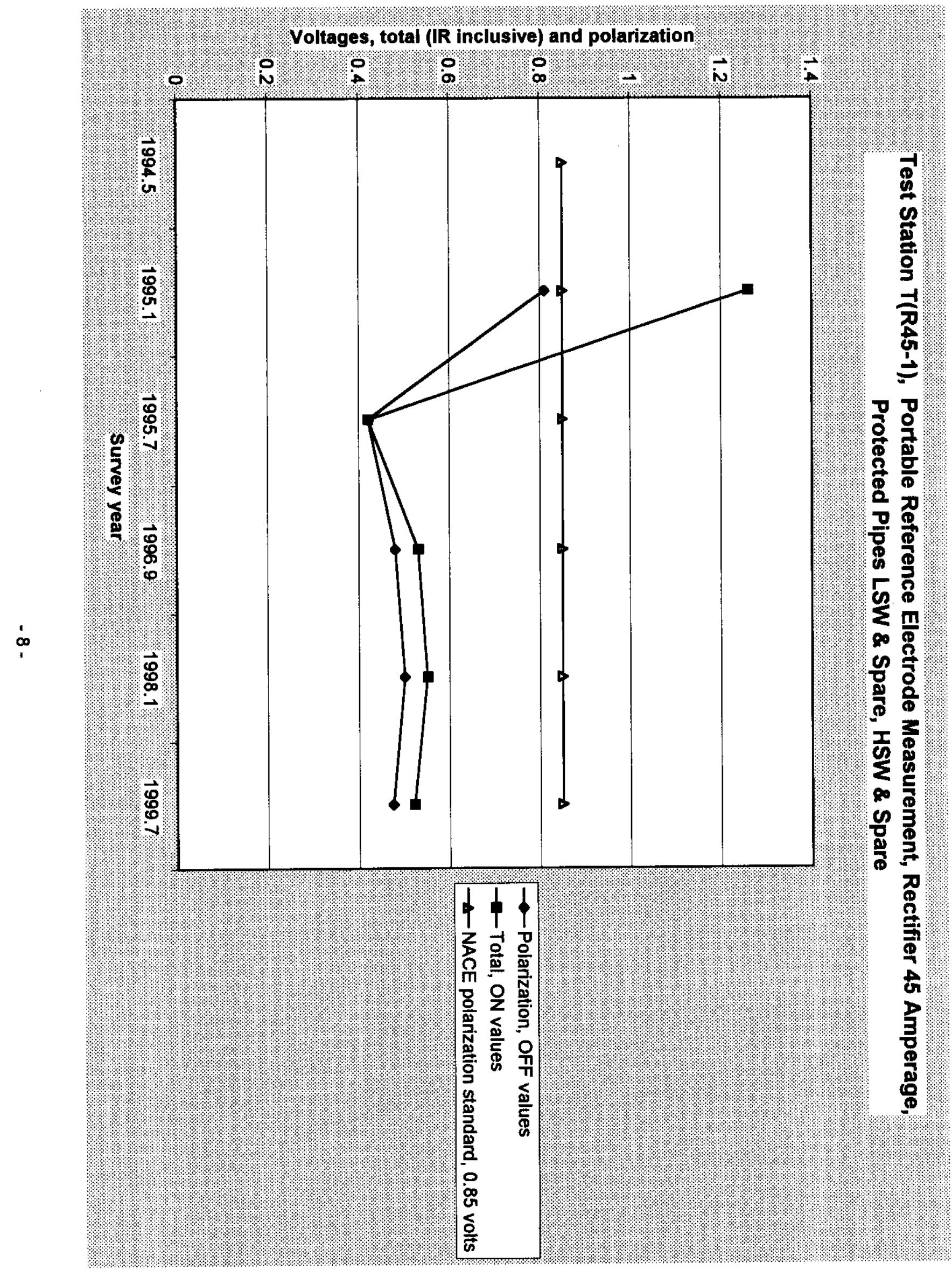

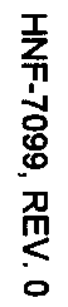




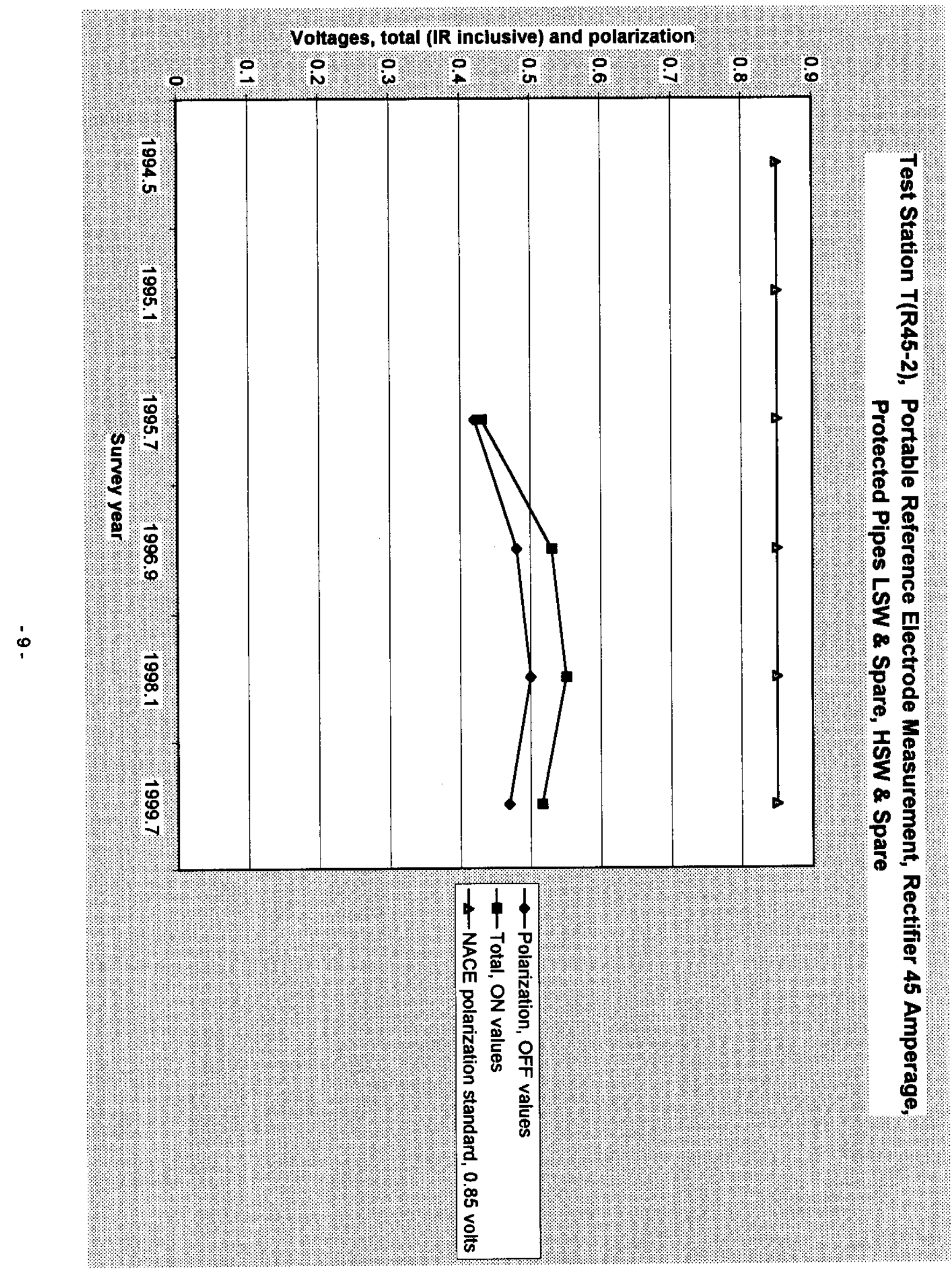

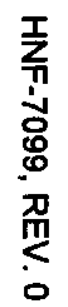




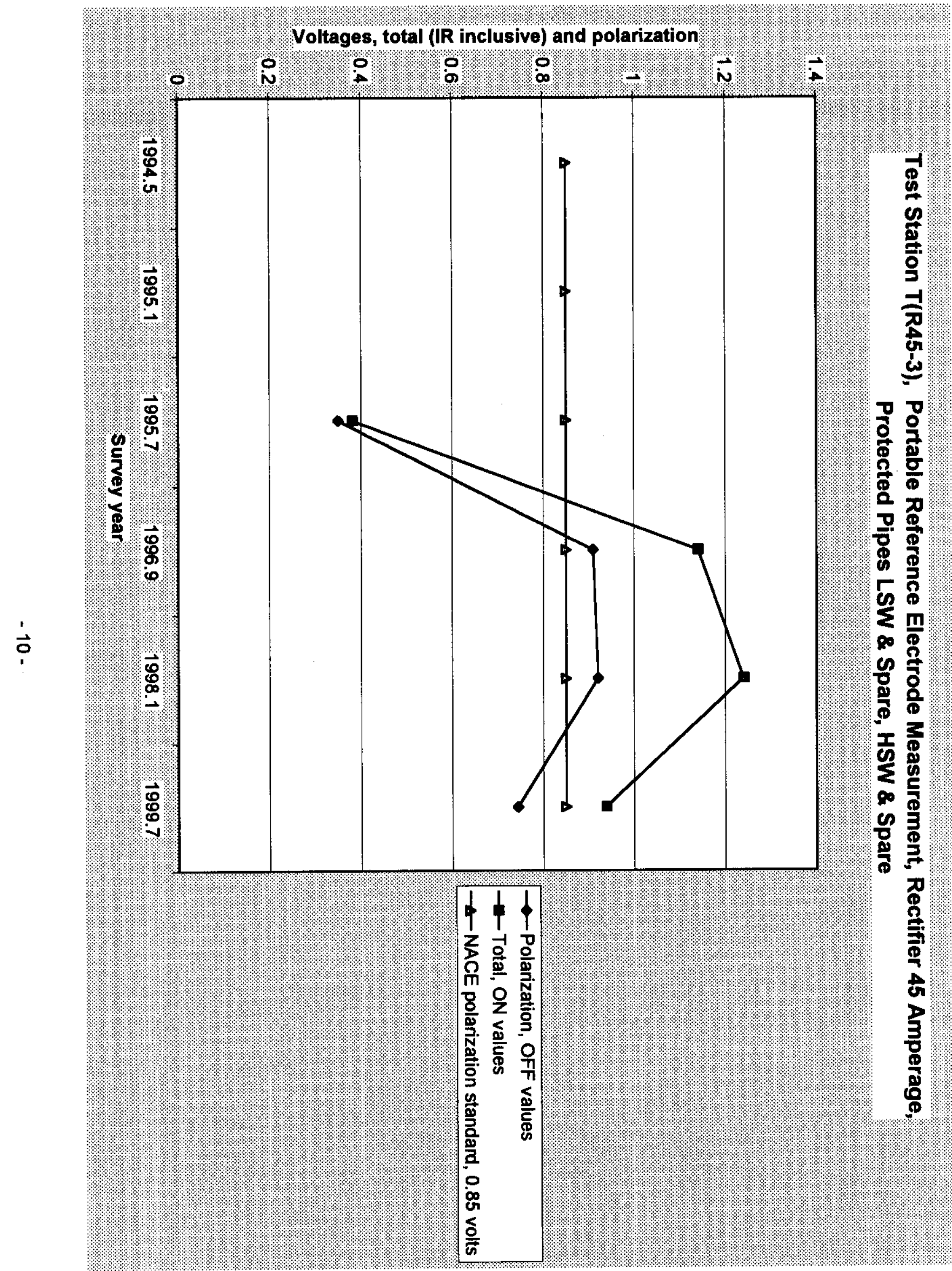

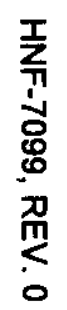




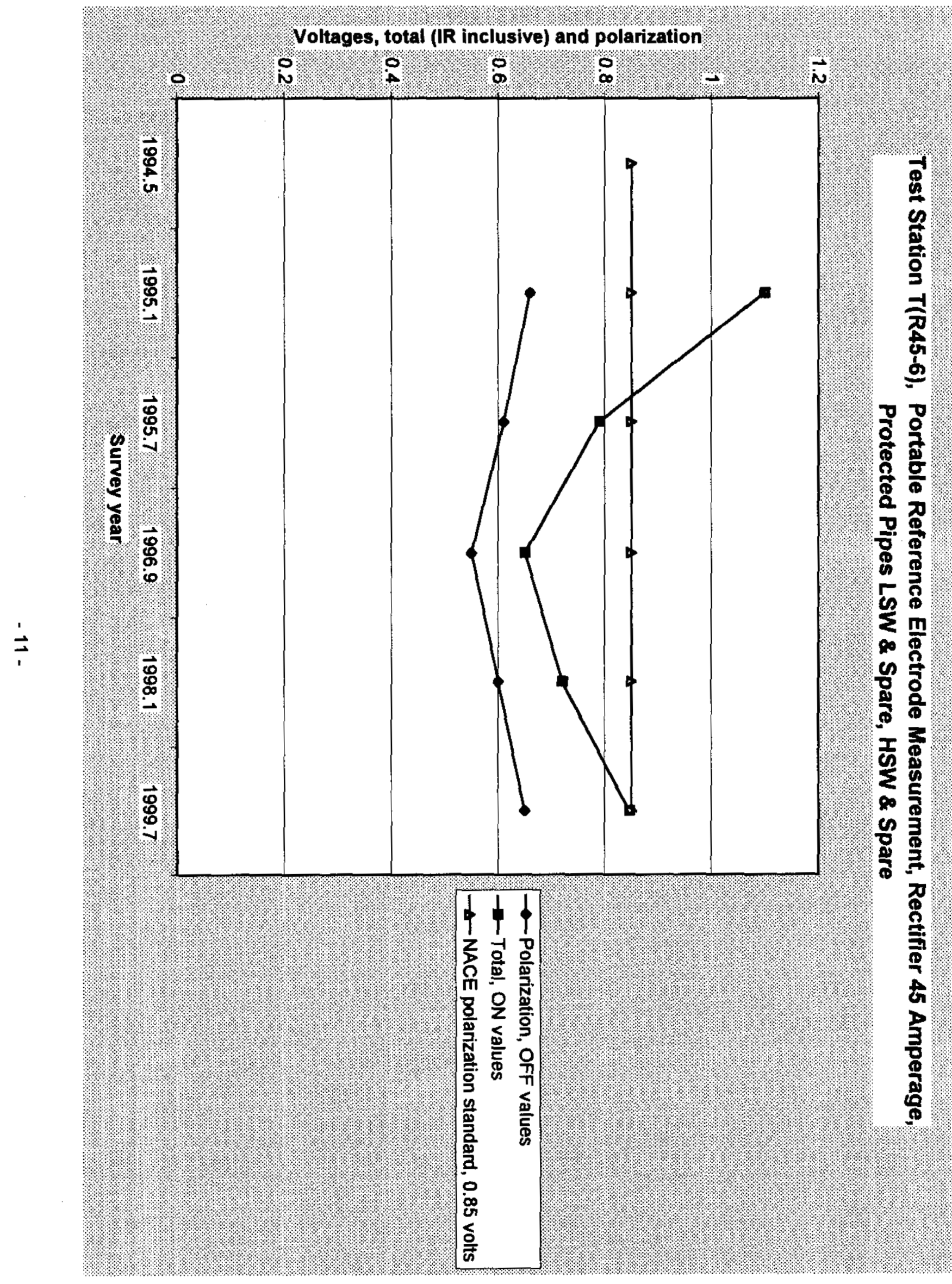

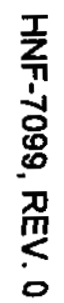




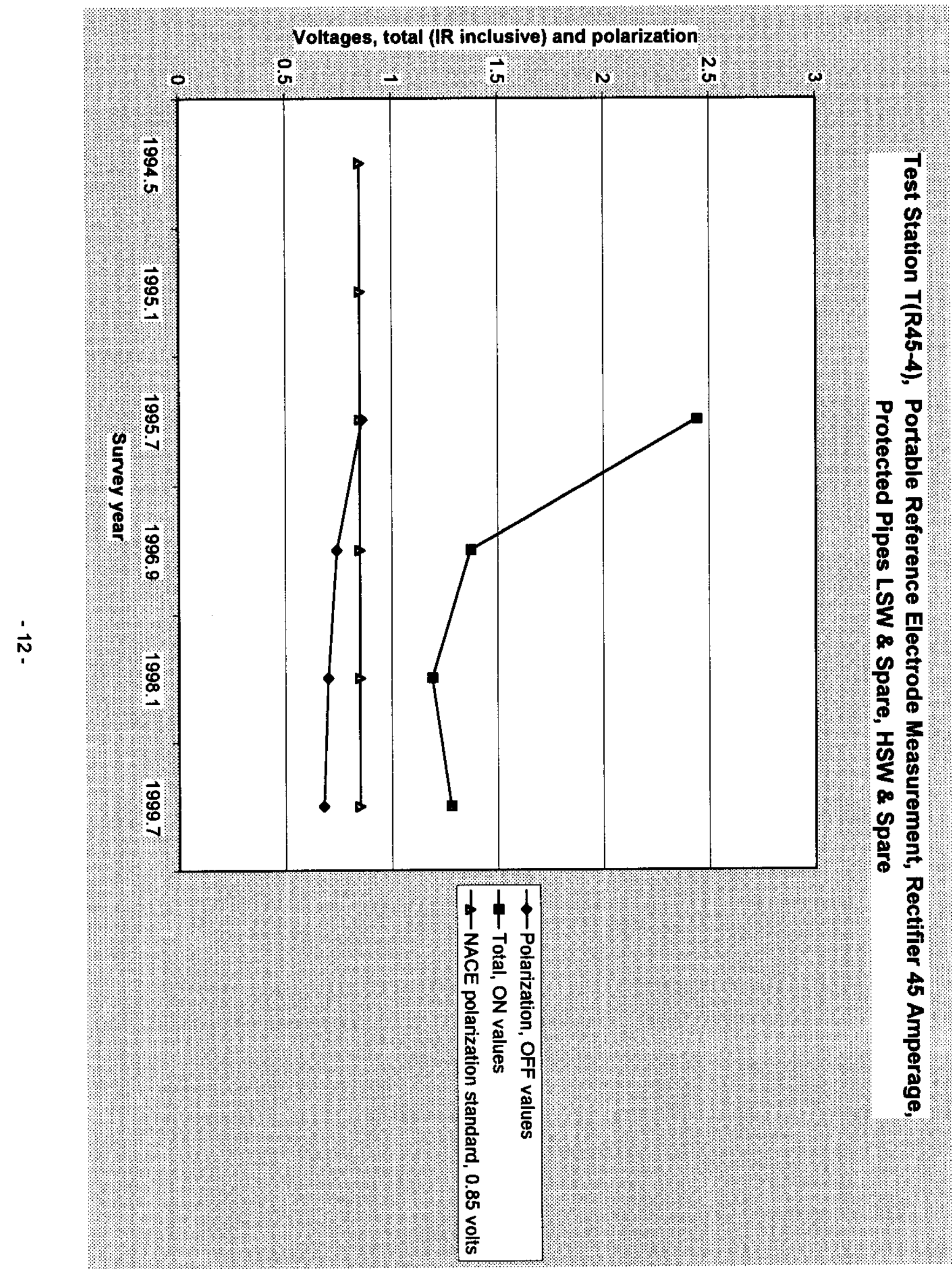




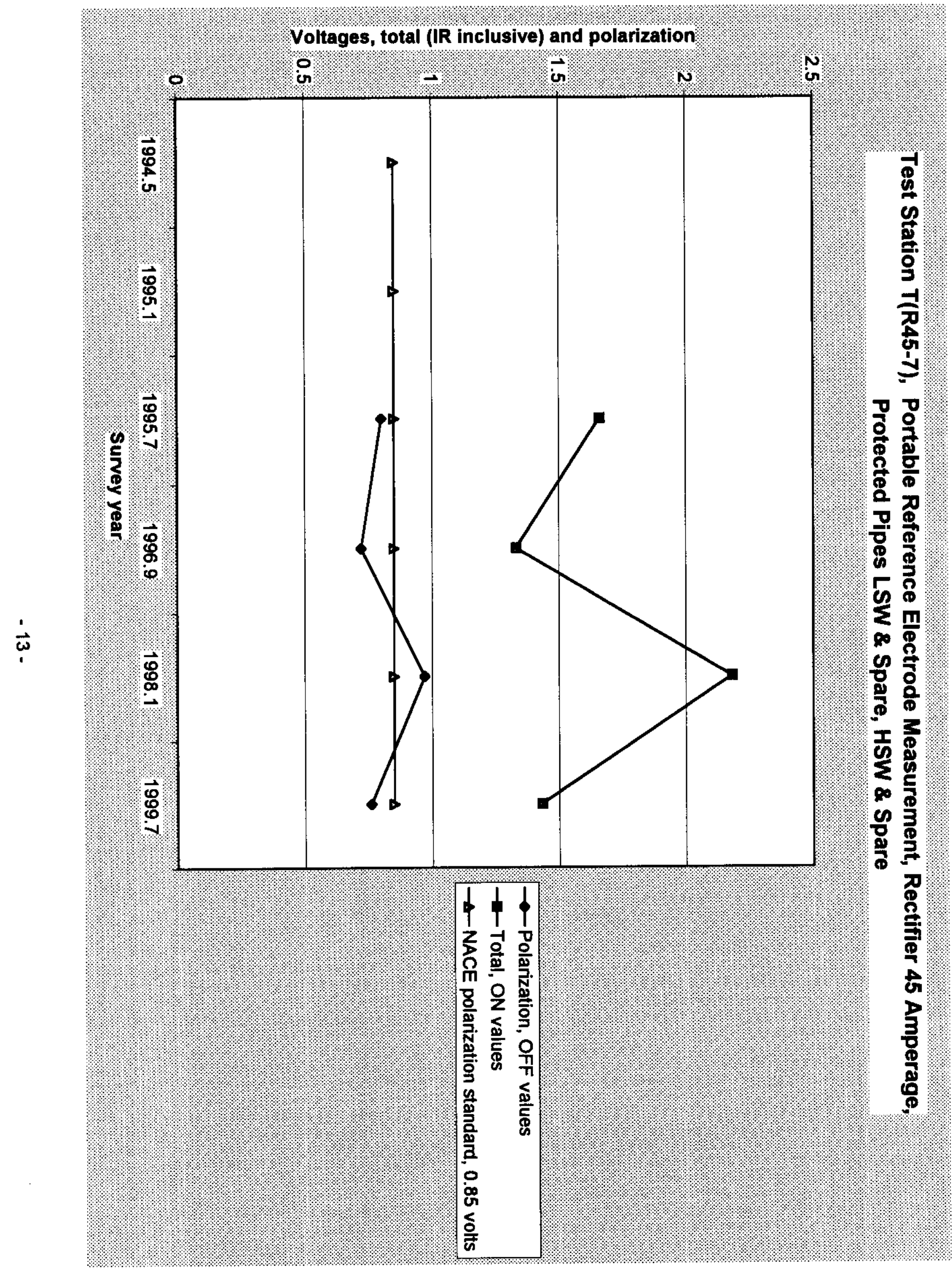

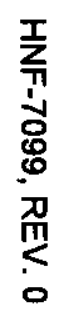




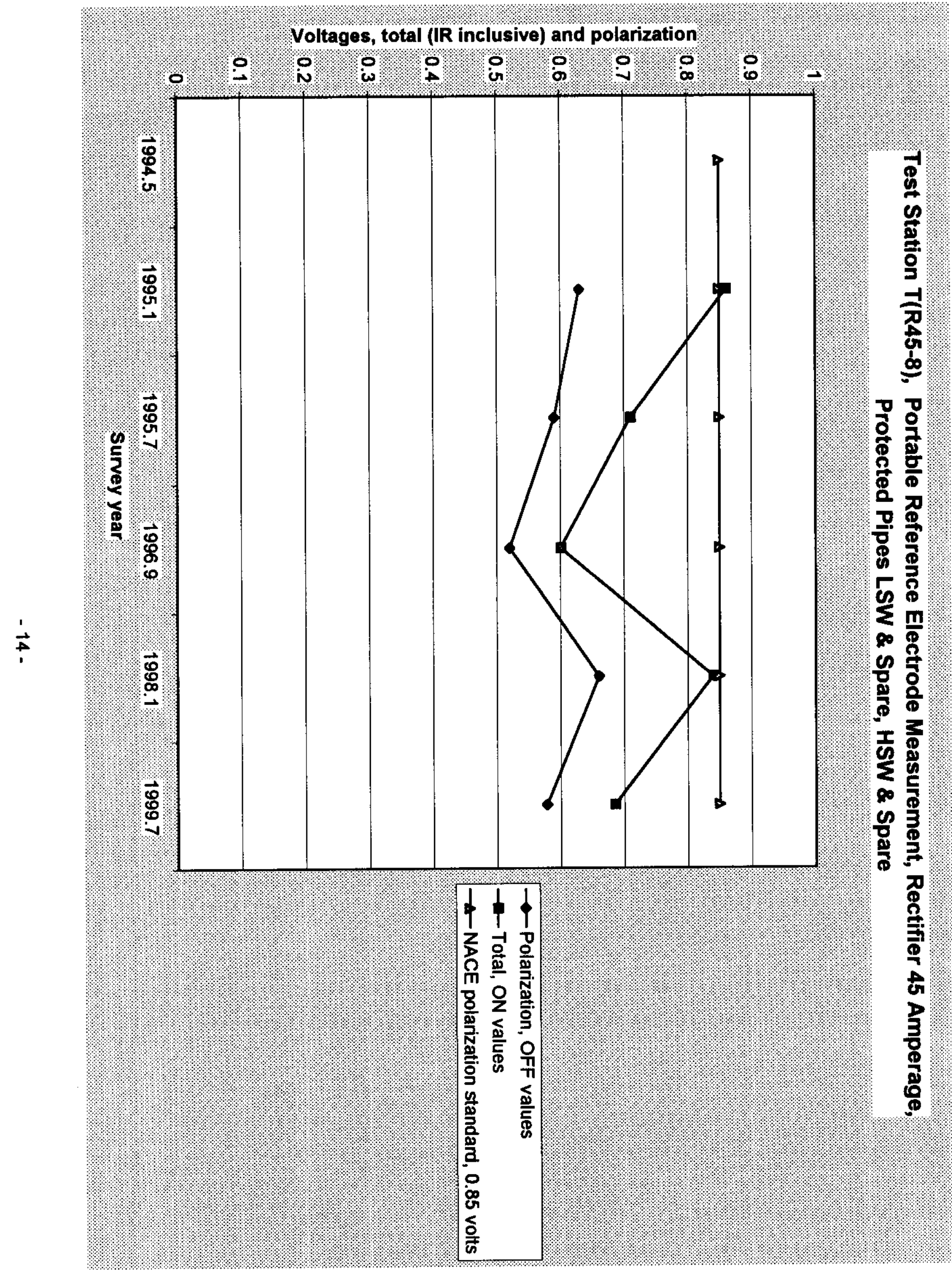




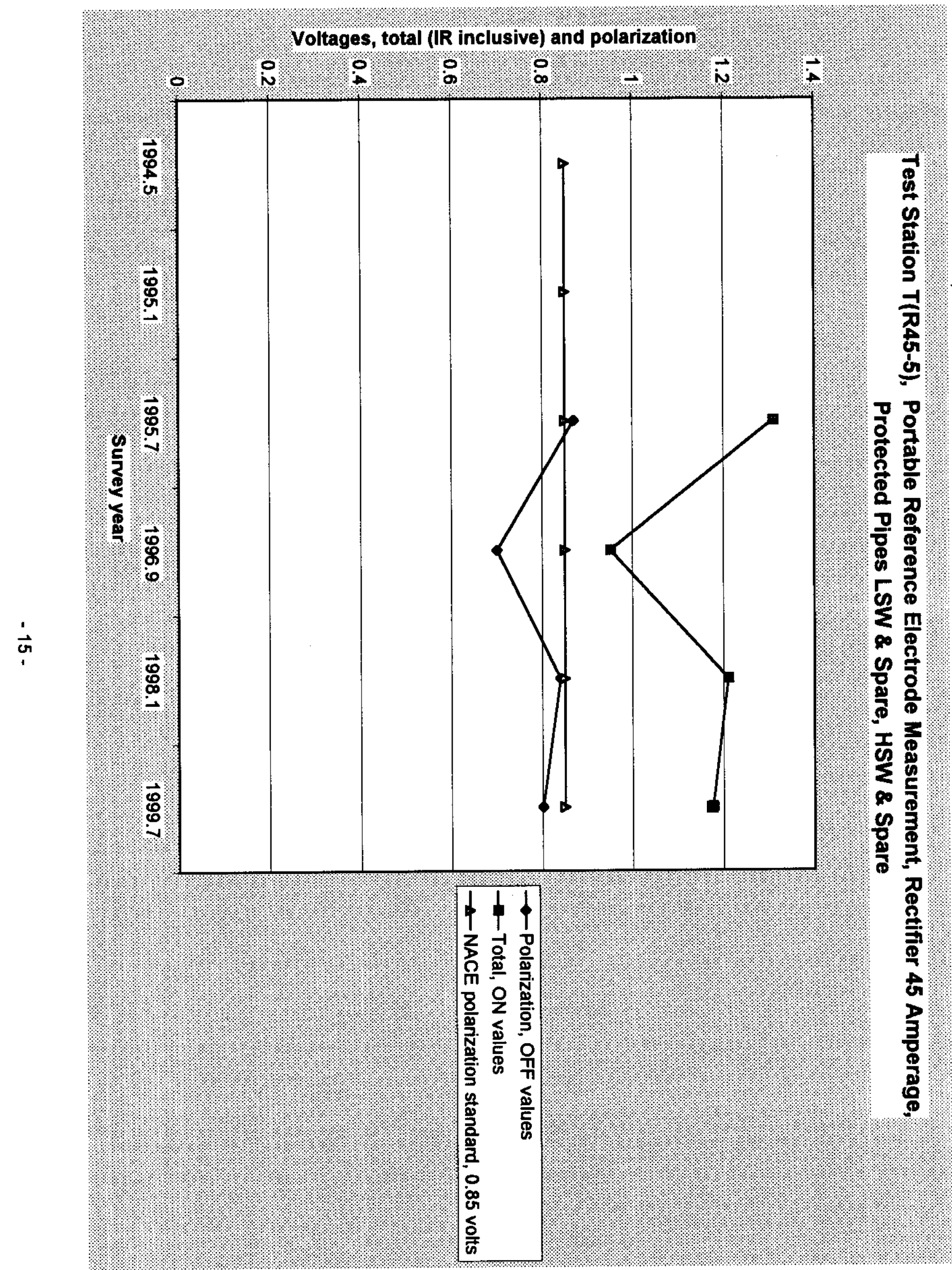




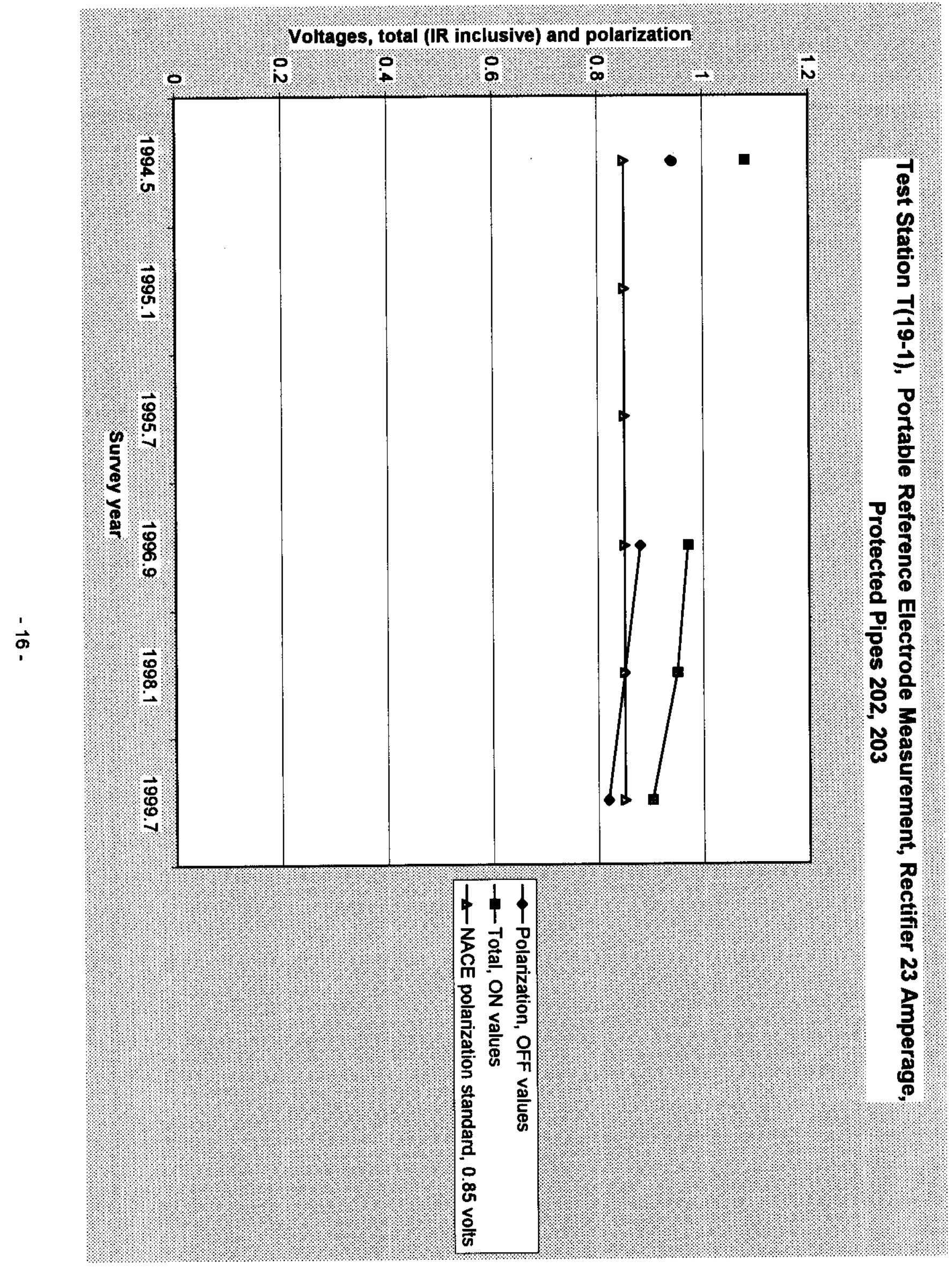

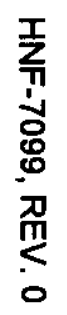




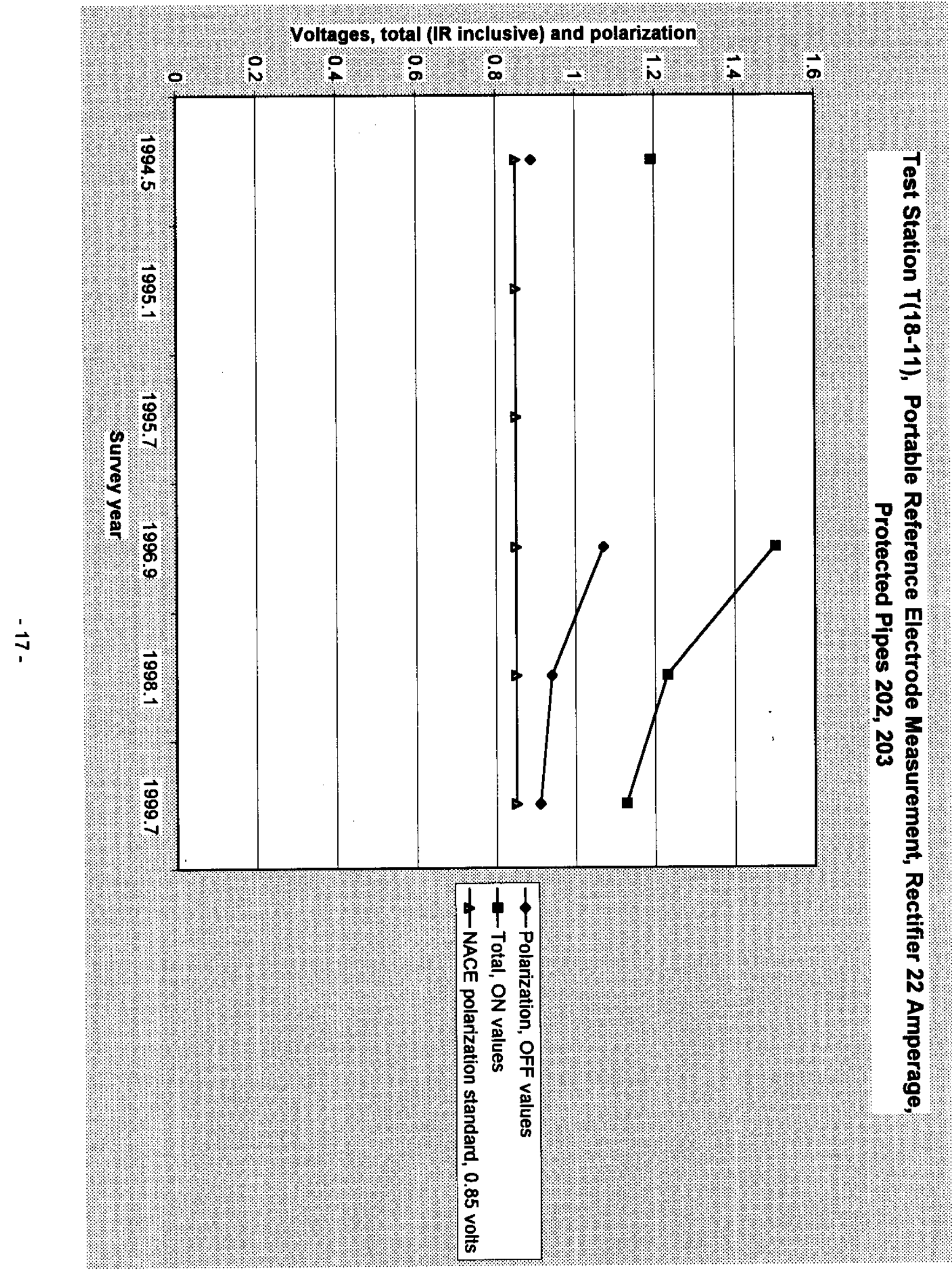




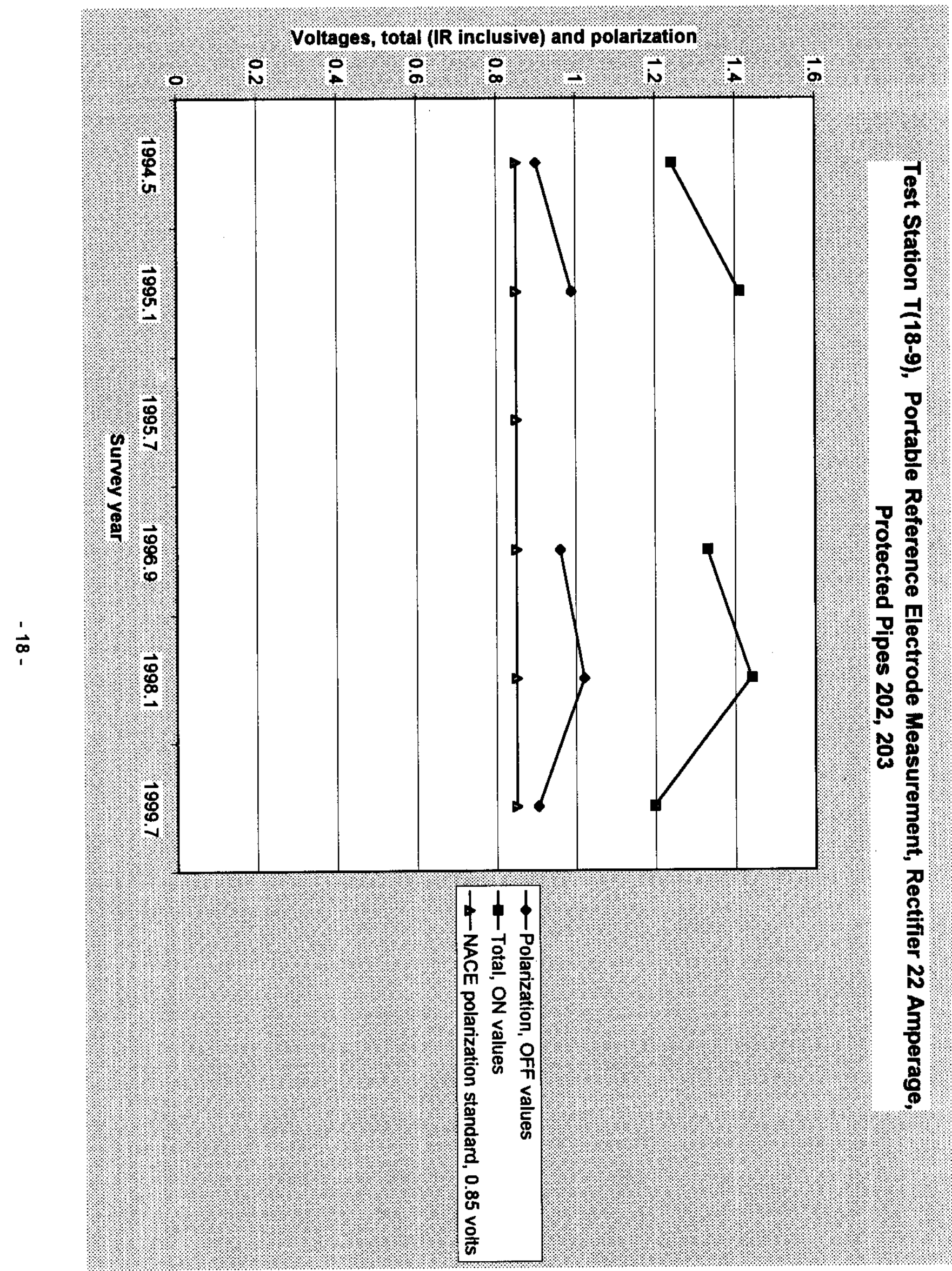

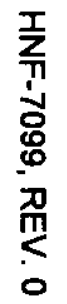




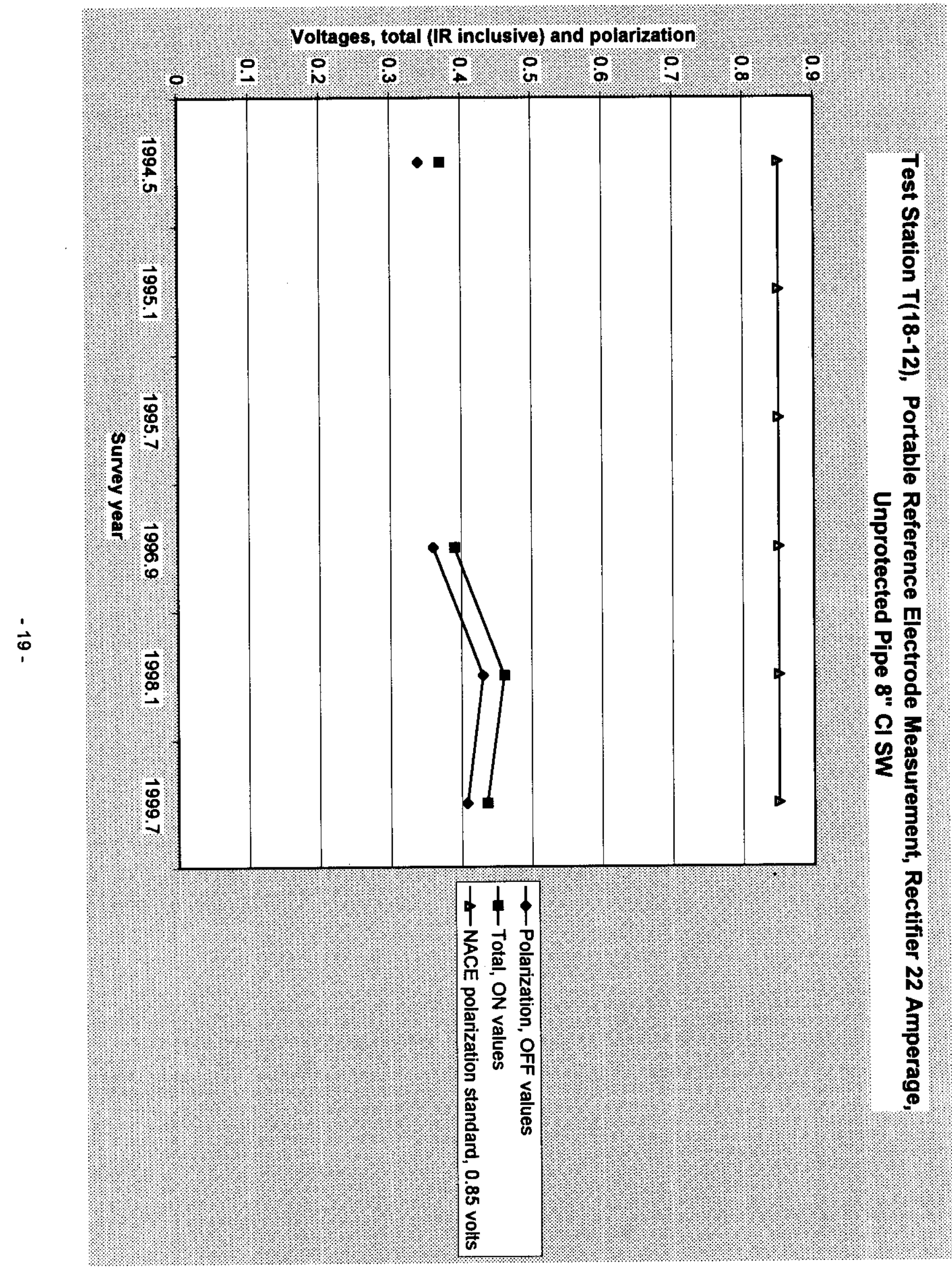




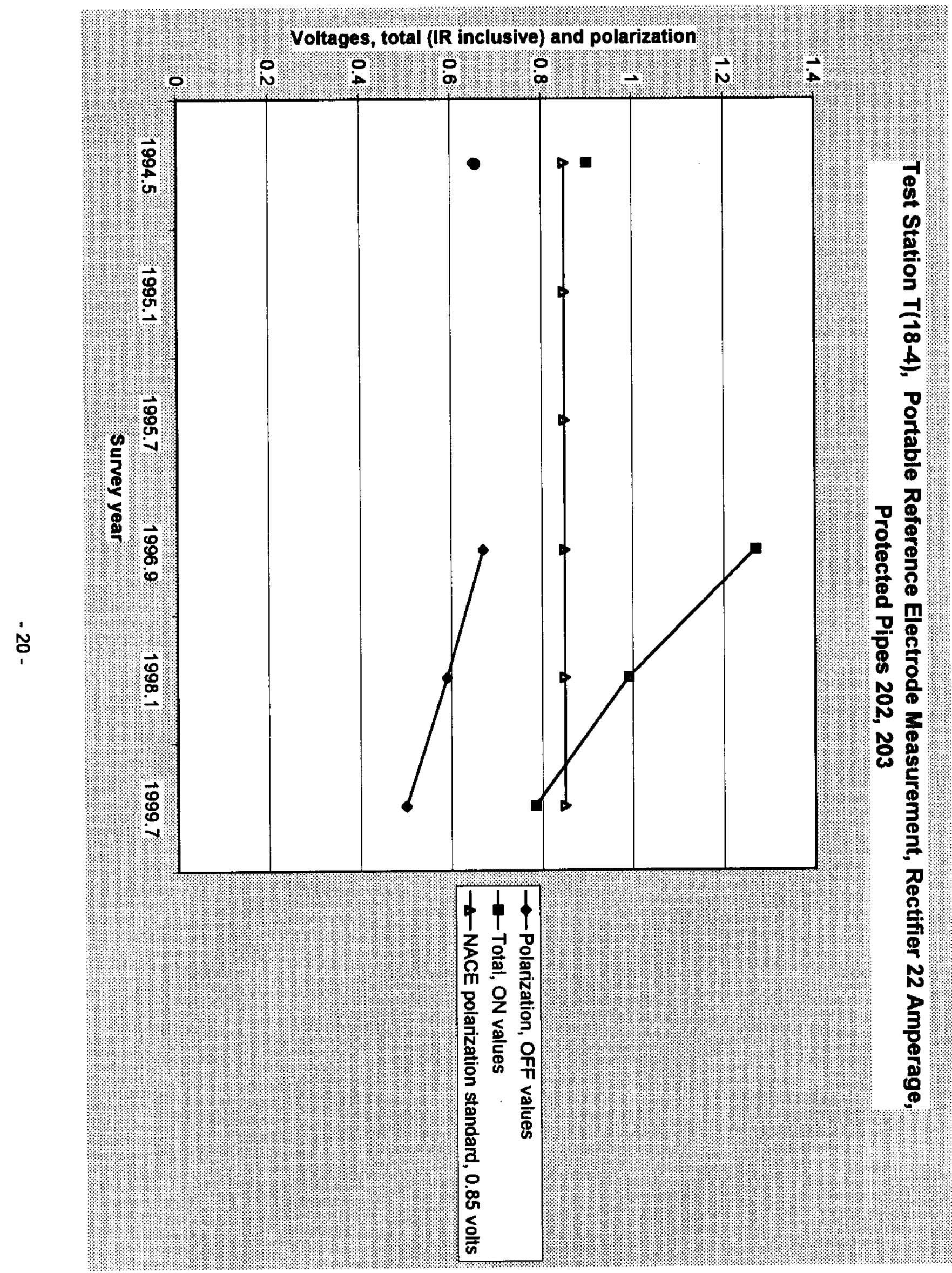




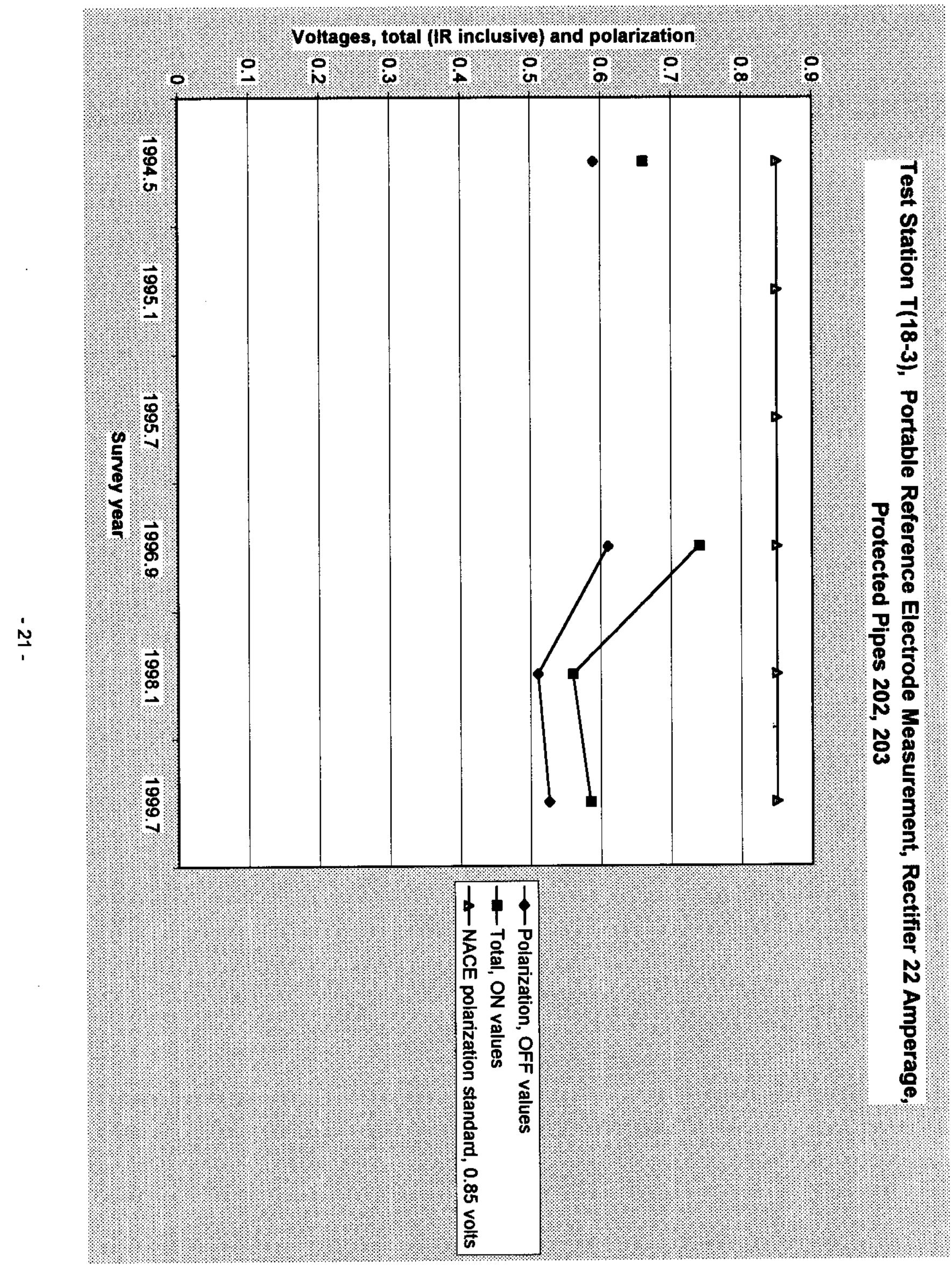




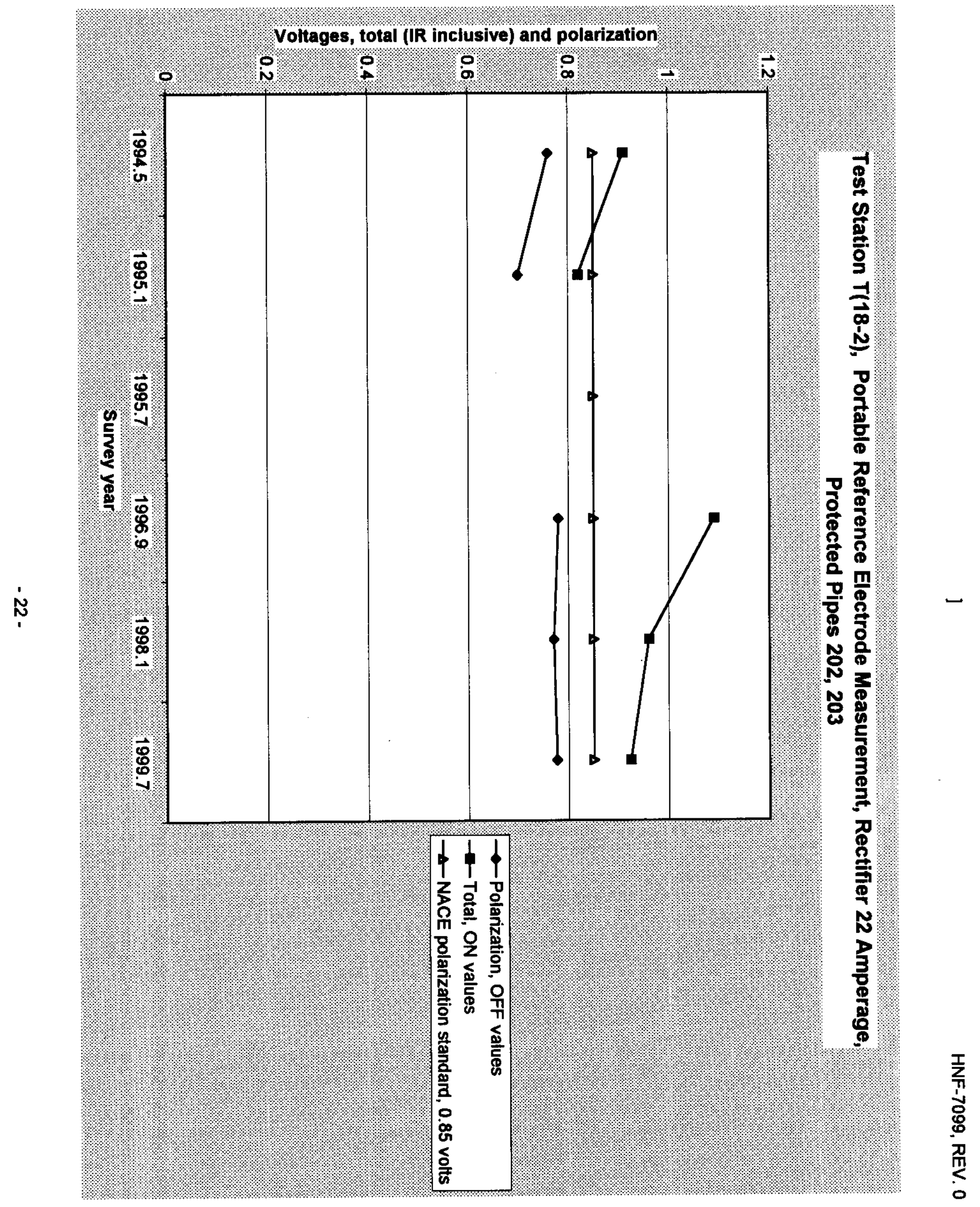




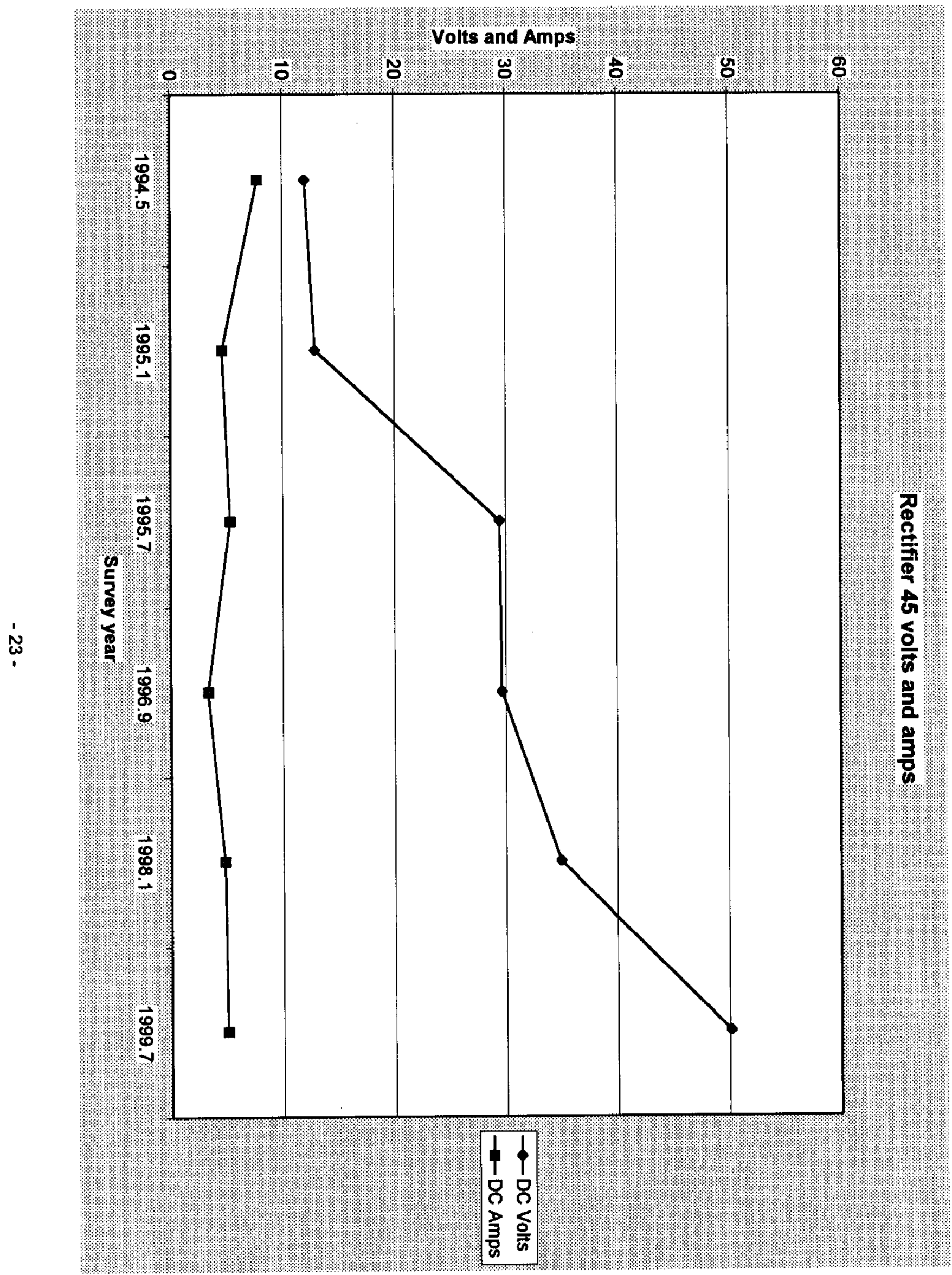

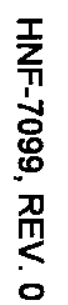




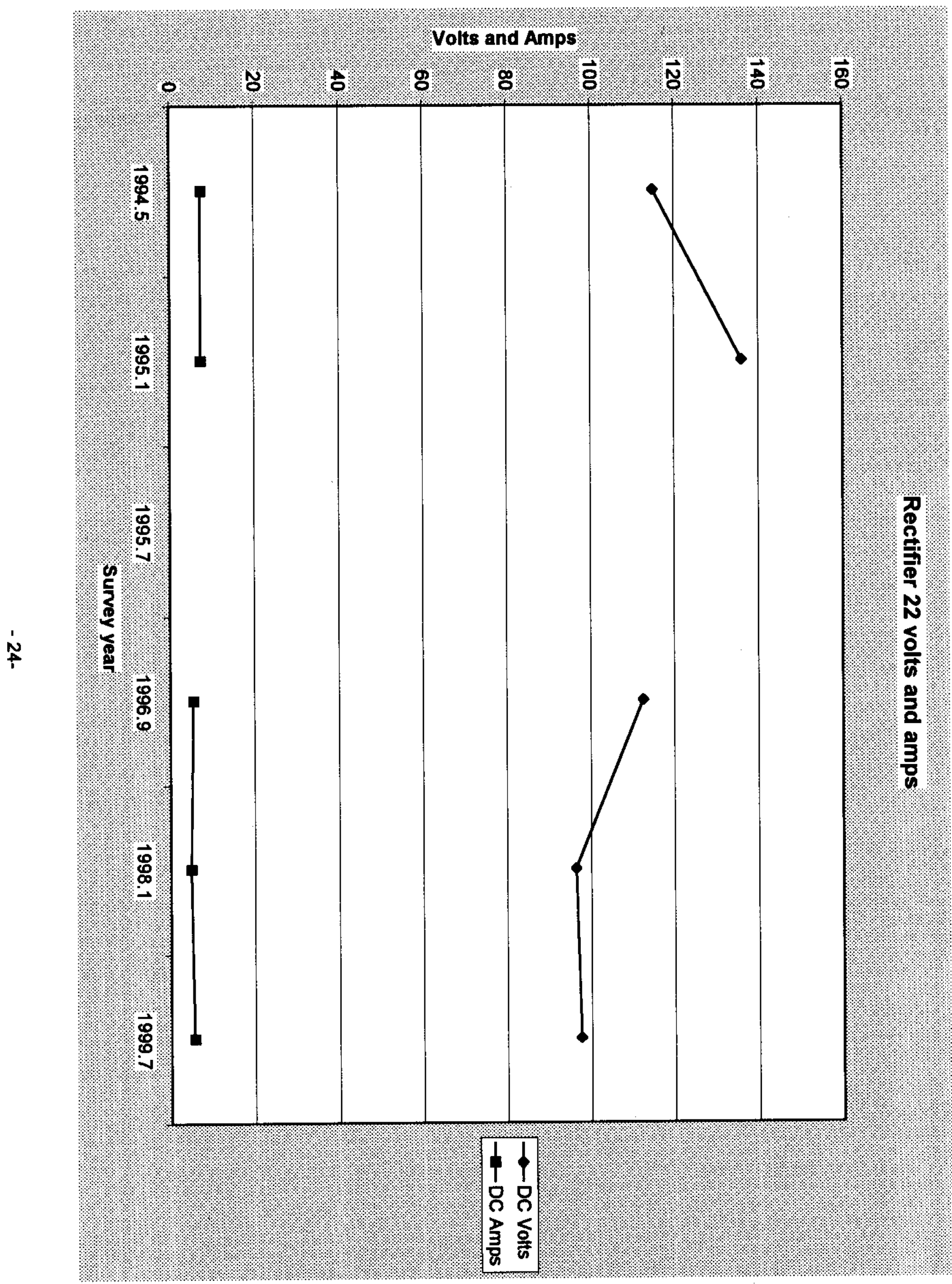

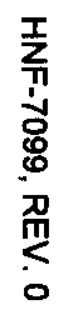




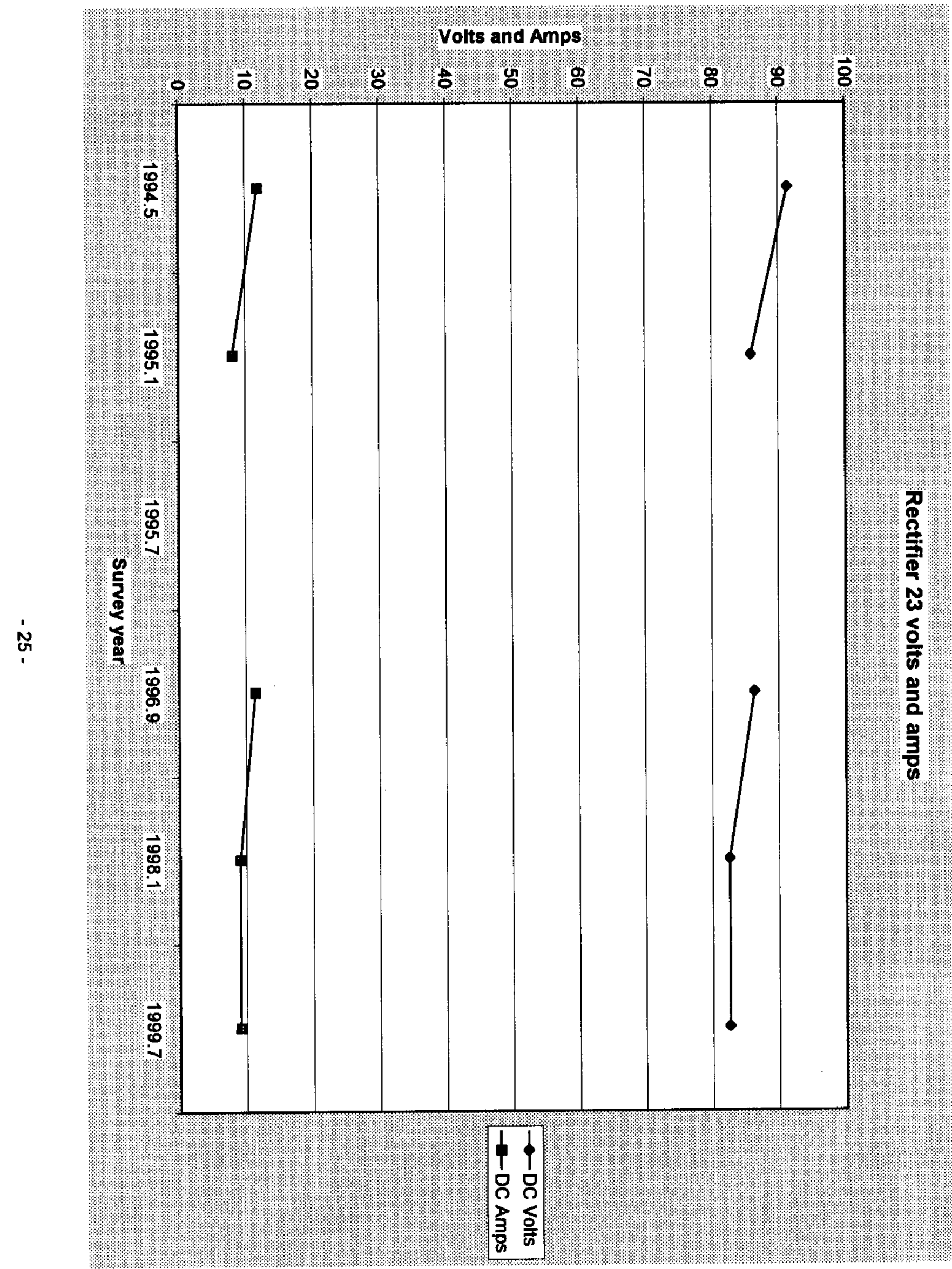

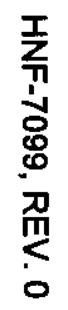

